\title{
PEDAGOGIA DA CASA: MEMÓRIA E DIÁLOGO DE SABERES - PRIMEIRAS NOTAS
}

\section{- PRISCILA DE OLIVEIRA XAVIER SCUDDER}

\author{
Universidade Federal de Mato Grosso
}

RESUMO

Neste artigo, tomamos as memórias, experiências cotidianas e saberes ancestrais, aprendidos no interior de casas chefiadas por mulheres negras, pobres e de periferia, como ponto de partida para o exercício de constituição de uma escrita e prática decolonial. Nosso intuito é, de par com a teoria da complexidade e da interseccionalidade, promover um diálogo de saberes que evidencie a existência de uma pedagogia potente no interior destas casas. A partir da construção de uma epistemologia da prática, de uma atividade auto/ otobiográfica, consideramos e reconhecemos esta pedagogia como uma herança ancestral, como um campo de força capaz de assegurar a vida de grupos vulneráveis frente às políticas genocidas, mas também de inspirar práticas docentes.

Palavras-chave: Mulheres negras. Pedagogia da casa. Decolonialidade. Interseccionalidade. Cotidiano.

\section{ABSTRACT PEDAGOGY OF THE HOUSE: MEMORY AND DIALOGUE OF KNOWLEDGE - FIRST NOTES}

In this article we take the memories, everyday experiences, and ancestral knowledge learned inside homes headed by black women in poor neighborhoods, as a starting point for the exercise of decolonial writing in practice. Our intention is, along with the theory of complexity and intersectionality, to promote a dialogue of knowledge that evidences the existence of a potent pedagogy within these houses. From the construction of an epistemology of practice, from a autobiographic/otobiographic activity, we consider and recognize this pedagogy as an ancestral heritage, as a force field capable of assuring the lives of vulnerable groups against genocidal policies, but also of inspiring teaching practices.

Keywords: Black women. Pedagogy of the home. Decoloniality. Intersectionality. Daily routine. 


\section{RESUMEN PEDAGOGÍA DE LA CASA: MEMORIA Y DIÁLOGO DE}

\section{SABERES - PRIMERAS NOTAS}

En este artículo tomamos las memorias, experiencias cotidianas y saberes ancestrales aprendidos en el interior de casas encabezadas por mujeres negras, pobres y de periferia como punto de partida para el ejercicio de constitución de una escritura y práctica decolonial. Nuestra intención es, de par con la teoría de la complejidad y de la interseccionalidad, promover un diálogo de saberes que evidencie la existencia de una pedagogía potente en el interior de estas casas. A partir de la construcción de una epistemología de la práctica, de una actividad auto / otobiográfica consideramos y reconocemos esta pedagogía como una herencia ancestral, como un campo de fuerza capaz de asegurar la vida de grupos vulnerables frente a políticas genocidas, pero también de inspirar prácticas docentes.

Palabras clave: Mujeres negras. Pedagogía de la casa. Descolonialidad. Interseccionalidad. Todos los días.

O gesto de escrever é acompanhado, entre outras coisas, por um desejo de pensar profundamente um problema. Os problemas podem ter os tamanhos e contornos da macroeconomia, da longa duração, das estruturas das grandes máquinas institucionais ou da vida cotidiana. A localização dos problemas em uma destas dimensões não indica que um ou outro ocupa um degrau inferior em alguma escala. Os acontecimentos da existência, da vida de todo dia, são atravessados pelas diretrizes político -econômicas do sistema-mundo capitalista e são fontes e pontos de partida para estudar também as questões canonizadas e revestidas de importância.

Michel de Certeau define o cotidiano como:

[...] aquilo que nos é dado (ou que nos cabe em partilha), nos pressiona dia à dia, nos oprime, pois existe opressão do presente. Todo dia, pela manhã, aquilo que assumimos, ao despertar, é o peso da vida, a dificuldade de viver, ou de viver nesta ou noutra condição, com esta fadiga, com este desejo. O cotidiano é aquilo que nos prende intimamente, a partir do interior. É uma história a meio caminho de nós mesmos, quase em retirada, às vezes velada. Não se deve es- quecer este 'mundo memória' [...]. É um mundo que amamos profundamente, memória olfativa, memória dos lugares da infância, dos prazeres. (CERTEAU, 2013, p. 31)

Quando escolhemos trabalhar com nossas próprias memórias e vivências, percebemos que qualquer discurso que categorize a importância de temas, a partir de alguma hierarquização arbitrária, inspirada em teorias hegemônicas eurocêntricas, "verdadeiras", supostamente capazes de definir o que é mais ou menos relevante, mais ou menos digno de ser analisado, não possui utilidade.

o espaço onde o cotidiano é tecido com mais proximidade e complexidade é o da casa. É nele que sentimos a opressão do presente, das políticas econômicas, do racismo que define os postos no mercado de trabatho e promove genocídios, das violências e injustiças do patriarcado, da fome, enfim, da manutenção da vida. Todas estas opressões são sentidas no corpo, alvo preferencial e constante do poder. Corpo que testemunha, carrega inscrições, narrativas, memórias e ensinamentos. 
Em "Para além do bem e do mal", Friedrich Wilhelm Nietzsche compartilha um de seus aprendizados: "Passo a passo, fui descobrindo que até o presente, em toda grande filosofia se encontram enxertadas não apenas a confissão espiritual, mas suas sutis 'memórias', tanto se assim o desejou seu autor quanto se não se apercebeu disso" (NIETZSCHE, 2009, p. 15).

De fato, todo escrito é, em grande medida, autobiográfico. Em nosso caso, vasculhamos coisas pensadas, ditas, intuídas, sentidas e aprendidas no espaço da casa e na relação com os mais velhos, pois reconhecemos neles saberes com os quais queremos dialogar por serem campos de força, por possuírem uma potência capaz de instrumentalizar a vida.

Este texto foi escrito a muitas mãos. As minhas mãos unidas às mãos de minhas avós, de meus pais, filhos e neta. Foi pensado como uma trilogia, por isso a indicação "primeiras notas" no subtítulo. As primeiras personagens com quem dialogamos são nossas avós, com elas rememora-se e ensaia-se uma epistemologia da prática, ou seja, "uma forma de entender-se com a prática, essa como sendo fruto das tensões e conquistas próprias da condição humana" (MONTEIRO, 2011, p. 21). Esta deliberação não foi aleatória ou coisa que se assemelhe, pelo contrário, partiu de uma decisão política de respeitar o tempo das experiências, de pensar o que se faz e com quem se faz, de registrar a importância de conhecimentos aprendidos oralmente, na vivência intergeracional, dos saberes produzidos por e em um grupo familiar. Não se trata de uma família qualquer, ainda que seja uma família comum, trata-se de uma família que tem pés fincados em um subúrbio carioca, em um território periférico e que migra, em parte, para outra região do Brasil. Trata-se daquilo que se aprende em casa, no lugar onde:

[...] as famílias se reúnem para celebrar os ritmos do tempo, confrontara experiência das gerações, acolher os nascimentos, solenizar as alianças, superar as provas, todo aquele longo trabalho de alegria e de luto que só se cumpre 'em casa', toda aquela lenta paciência que conduz da vida à morte no correr dos anos. (CERTEAU, 2013, p. 206)

Entre as motivações que geraram este texto, está a de afirmar a importância de mulheres negras para a sustentação de grupos familiares, para a sobrevivência de seus descendentes e para a construção de um saber sobre a vida e para a vida. Outra razão é a decisão de dar testemunho sobre a história de vida de mulheres que, via de regra, não figuram em obras históricas, pedagógicas, artísticas etc., por conta dos lugares sociais, políticos, econômicos, culturais, étnicos que ocupam. E ainda, evidenciar que as memórias portam segredos, "feitiços" que nos ajudam a existir em um mundo absolutamente hostil e perigoso para negros, indígenas e demais grupos que se distanciam de um padrão eurocentrado.

As mulheres negras de periferia, em geral avós, que além de terem criado seus filhos se ocupam também da criação de netos e bisnetos, ativam práticas criadoras de soluções para demandas diárias. Demandas intrinsecamente ligadas à garantia ou não da existência. São elas que administram parcos recursos, que elaboram refeições, aproveitando escassos provimentos, que saem de casa com as marmitas vazias, que deixam de comer para que seus filhos comam, que constroem relações com os vizinhos, para que seus filhos gozem de algum cuidado enquanto se afastam para o trabalho. São elas que criam táticas para que frequentem a escola, que percorrem e cartografam o bairro, conhecem os armazéns, negociam com os comerciantes, atentam para o movimento dos moradores, com vistas, entre tantas coisas, a amealhar um tanto de segurança para seus filhos. Sobre o modo como conseguem realizar esta enormidade de tarefas e desdo- 
brar-se para dar conta da própria vida, é um "mistério" que não pode ser investigado, descrito e/ou entendido com "distanciamento".

Acerca da cartografia do bairro, Michel de Certeau considera que:

O bairro é um universo social que não aprecia muito a transgressão; esta é incompatível com a suposta transparência da vida cotidiana, com a sua imediata legibilidade. [...]. o bairro é um palco 'diurno' cujos personagens são a cada instante, identificáveis no papel que a conveniência lhes atribui: a criança, o pequeno comerciante, a mãe de família, o jovem, o aposentado, o padre, o médico, máscaras e máscaras por trás das quais o usuário do bairro é 'obrigado' a se refugiar para continuar usufruindo dos benefícios simbólicos com os quais podem contar. [...] Quem é quem e faz o que? De onde vem este novo freguês? Quem é o novo locatário? (CERTEAU, 2013, p. 51)

Todas estas interrogações são fundamentais para que as mulheres negras, pobres, chefes de família saiam para o trabalho. Elas são preparatórias, são revisadas antes que deixem a casa. Lembro que quando criança, minha avó paterna nos mandava com frequência ao armazém de secos e molhados de Seu Manoel, um português que anotava as compras na caderneta que era paga mensalmente. Era sempre bom, pois antes de ir perguntávamos se podíamos anotar um doce, e a avó sempre dizia sim. Nas vezes em que íamos ao armazém com dinheiro, não havia preocupação com o fato de não sabermos fazer contas, pois havia confiança de que o troco seria dado corretamente. Seu Manoel sempre perguntava: - Como vai Dona Mocinha'? Como anda da bronquite? Estas gentilezas corroboram com a assertiva de Certeau de que no bairro: "[...] comprar não é apenas trocar dinheiro por alimentos, mas além disso ser bem servido, quando se é bom freguês. [...]. É fruto de um longo costume re-

1 Mocinha era o apelido de minha avó. Só a família e seus amigos e conhecidos de longa data chamavam assim Marieta de Oliveira. cíproco pelo qual cada um sabe o que pode pedir ou dar ao outro, em vista de melhorar a relação com os objetos de troca" (CERTEAU, 2013, p. 52).

Minhas avós podem ser tidas como "heroínas obscuras de quem sou devedora e assim mesmo as quais me assemelho" (CERTEAU, 2013, p. 32). Tantas mulheres negras se assemeIham a elas e entre si, e para escrever sobre estas mulheres sem submetê-las a um discurso que as desqualifique, é preciso eleger as ferramentas teórico-metodológicas com cuidado.

Não há nesta escrita nenhuma intenção de simular uma assepsia, de afirmar a hybris del punto cero (CASTRO-GOMEZ, 2009), ou seja, a falsa ideia ou argumentação de que quem escreve ocupa um lugar privilegiado de observação, pois já sabemos que toda pesquisa, toda escrita, toda investigação é contaminada pela estreita relação entre aquele que observa e escreve e aquilo ou aqueles que são observados e tomados/tornados como "problema". Afinal,

El ideal ya no sería el de la pureza y el distanciamiento, sino el de la contaminación y el acercamiento. Descender del punto cero implica, entonces, reconocer que el observador es parte integral de aquello que observa y que no es posible ningún experimento social en el cual podamos actuar como simples experimentadores. Cualquier observación nos involucra ya como parte del experimento. ${ }^{2}$ (CASTRO-GOMEZ, 2009, p. 89).

É certo que a maior razão para o saber construído e ensinado pelas mulheres negras ter permanecido ausente dos livros e debates escolares e acadêmicos, deve-se ao fato de que a escrita da história coube, quase que exclusivamente e durante longo tempo, aos ho-

2 "O ideal não seria mais o de pureza e distanciamento, mas o de contaminação e proximidade. Descender do ponto zero implica, então, reconhecer que o observador é parte integrante do que ele observa e que nenhum experimento social é possível, no qual podemos agir como meros experimentadores. Qualquer observação já nos envolve como parte do experimento". (CASTRO-GOMEZ, 2009, p. 89) 
mens brancos e de elite. Assim, o silêncio sobre o papel fundamental que exerceram (e exercem) na estrutura de um país como o Brasil, por exemplo, onde a maior parte das família é chefiada por mulheres, conforme demonstrou pesquisa do Instituto Brasileiro de Geografia e Estatística [PNAD 2001-2015], só se explica, por algo que denuncia a própria impossibilidade de neutralidade, o racismo epistêmico. Acerca do tema, é possivel entender que:

O racismo e o sexismo epistêmicos são as formas de racismo e sexismo mais veladas no sistema global que todos habitamos, o «sistema mundo capitalista/ patriarcal moderno/colonial ocidentalizado/cristianizado». [...] 0 racismo / sexismo epistêmico vê o conhecimento 'não-occidental' como inferior ao conhecimento 'Occidental'. Dado que o racismo epistêmico está envolvido com o patriarcado judaico-cristão e seu sexismo epistêmico, a ciência que tem o Occidente como centro é uma forma de racismo / sexismo epistêmico que privilegia o conhecimento masculino 'ocidental' como o mais alto conhecimento do mundo. (GROSFOGUEL, 2011, p. 3)

Neste sentido, a proposta de análise interseccional converge com os estudos decoloniais, pois se estes denunciam a existência de um racismo/sexismo epistêmico, a perspectiva interseccional afirma que as questões de raça, classe e gênero são indissociáveis. De fato, estas dimensões da vida abraçam-nos como rizomas, não sendo possível limitar suas importâncias, tampouco os efeitos de poder que produzem. O certo é que podemos constatar, através dos dados de pesquisas como as do IBGE, ou apenas observando a cor da maioria das pessoas que vivem nas periferias, que exercem trabalhos informais ou que compõem as estatísticas do desemprego, ou ainda da quantidade de crianças que possuem apenas o nome das mães em sua certidão de casamento, a pertinência das análises decoloniais e interseccionais.
Dialogamos com a vida de mulheres próximas a nós, e isso se deve ao fato de sermos, ao mesmo tempo, alvo de seus cuidados e afetos e aprendizes, de trazermos no corpo as marcas de seus saberes. Em nós reverberam suas experiências, ressoam seus ditados, assim como em nós, seus modos de fazer, suas maneiras de estar e pensar o mundo são recriados, reinventados, rememorados. Neste exercício, “A escrita é a ponte entre nossos espíritos e os seus espíritos" (COUTO, 2003 p. 126).

$E$, afinal, o modelo de ciência positiva não explica tudo. Não pode explicar tudo. Há domínios da vida imperscrutáveis pela dogmática. A força das normas não submete as pulsões da vida, dos instintos, dos quereres, daquilo que já nem se sabe indicar de onde vem, como as coisas e os saberes ancestrais. Há movimentos produzidos nos corpos quando um atabaque explode, quando mãos velhas e cansadas tocam uma descendente, quando cantam e repetem histórias, e reinscrevem os mortos nas narrativas. Ao recapitular o vivido, cria-se de fato um novo capítulo, uma nova lembrança, uma ligação entre gerações, como se todos os que se foram permanecessem não apenas ao lado, observando em volta, mas vivendo em cada um. Parece mesmo como uma "Cicatriz tão longe de uma ferida tão dentro: a ausente permanência de quem morreu" (COUTO, 2003 p. 15).

Os mais velhos, aqueles que tomam a incumbência de compor um enredo que envolva e mantenha todos os moradores de uma casa pobre conectados, sabem que assim fazendo viabilizam certa possibilidade de existência a mais para o grupo e ao mesmo tempo que vão perdendo a força física vão se revestindo de uma força discursiva, que faz com que nosso "olhar pareça mais um modo de escutar" (COUTO, 2003 p. 16).

Minha avó paterna, Marieta de Oliveira, viúva aos trinta e dois anos de idade, mãe de 
cinco filhos, permaneceu viúva até os setenta e cinco anos, tempo em que faleceu. Lembrome de suas histórias de príncipes e fadas, mas o que mais carrego, o maior legado que deixou, foi a presença diária de meu avô através de suas recordações. Ela nos fez saber como ele chegava em casa após longos períodos no mar. Telegrafista da Marinha do Brasil, sempre trazia presentes para ela e os filhos. Sentava com a única filha ao colo, e punha os meninos ao redor de si. Possuo uma quantidade semfim de memórias e emoções e um amor grande por este avô com quem me sinto tão ligada, apesar dele ter falecido quando meu pai tinha tão somente seis anos de idade.

A casa de minha avó Marieta ficava na Rua Maria Tomázia, no final da principal avenida de Nilópolis, a Mirandela. Município da Baixada Fluminense, subúrbio do Rio de Janeiro, conhecido em todo Brasil graças à Escola de Samba Beija-Flor. Ao aproximar-se da casa, podia-se ler "Vila Jadyr", homenagem e demonstração de amor de meu avô para com sua filha. Logo ao adentrar o portão via-se que a parede da varanda exibia uma cena antiga representada em azulejos portugueses trazidos por meu avô de uma de suas viagens. A casa era bonita, com tacos na sala e azulejo hidráulico no restante. Tinha um quintal grande - meu avô era prevenido-, onde todos os filhos poderiam construir casas se desejassem. Meu pai fez isto. As janelas eram do tipo basculante e suas fechaduras sempre me fascinaram. Possuía ainda uma cisterna movida por um interessante sistema de copos de água e vários vizinhos se serviam dela quando faltava água na rua. Os vizinhos eram antigos, alguns conheceram meu avô, viram meu pai e tios, a mim, aos meus irmãos e primos crianças.

Lá havia sempre histórias, carinho, bolinho de chuva e mate gelado. Feitos por minha vó ou minhas tias. Havia muita coisa mais, mas por enquanto são estas lembranças que nos aquecem. Reconheço a casa de minhas avós em minha família a casa é pertença feminina -, nos versos de Breyner, escolhidos por Mia Couto (2003, s.p.):

No princípio, a casa foi sagrada

isto é, habitada

não só por homens e vivos

como também por mortos e deuses

Com minha avó Marieta aprendo sobre a importância da tradição oral, das histórias cotidianas, de registrar o que se viveu, de rememorar. Hoje imagino que toda aquela conversação que ela mantinha, todas as histórias que tecia, não apenas garantiram nossa unidade - dos netos especialmente -, mas também o sentimento de pertencimento, de aquilombamento, de ubuntu.

Havia mais, havia a fraternidade, a generosidade, a hospitalidade, o desprendimento, o partilhar dos alimentos, dos recursos, dos afetos. Toda vez que saíamos minha vó nos dava uma moeda, e soube por meu pai que ela fizera o mesmo com os filhos. Coisa antiga ensinar a arte de doar e doar-se. Esta moeda não era nossa, era para darmos caso alguém que precisasse nos pedisse, fosse na rua, fosse no trem. Recordo a história de uma de minhas tias. Um dia passeando por uma das ruas de Nilópolis, com sua filha que contava na época com nove anos de idade, minha avó olhou pela porta entreaberta de uma casa e avistou uma criança sobre a mesa. A criança era bem pequena, não se mexia. Ela e a filha aproximaram-se e notaram moscas pousadas sobre o corpo inerte. A pedidos da filha e sem opor resistências, minha avó adotou a criança, sua quinta filha, que aos sete anos de idade não andava, não falava e sequer tinha forças para espantar as moscas, devido à desnutrição.

Este conjunto de coisas aprendidas na casa de minha avó, estão em mim, a ele foram somados outros, e se, ao elaborar minhas sinte- 
ses, estes elementos permanecem, suspeito que seja em razão de que:

Nossos habitats sucessivos jamais desaparecem totalmente, nós os deixamos sem deixá -los, pois, eles habitam, por sua vez, invisiveis e presentes, nas nossas memórias e nos nossos sonhos. Eles viajam conosco. No centro desses sonhos aparece muitas vezes a cozinha, aquele 'compartimento quente' onde a família se reúne, teatro de operação das 'artes de fazer' e da mais necessária entre elas, 'a arte de nutrir'. (CERTEAU, 2013, p. 207)

Para sustentar esta escrita que quer reconhecer a potência dos ditos cotidianos, nos valemos, além da perspectiva interseccional, do "paradigma del pensamiento complejo". A primeira explicamos em parágrafos acima, e quanto à segunda, podemos dizer, recorrendo a Castro-Gomez, (2009, p. 87), que se trata, entre outras coisas, de "La idea de que cada uno de nosotros es un todo físico-químico-biológico-psicológico-social-cultural, integrado en la compleja trama del universo. [...]. Vivimos en un mundo que ya no puede ser entendido sobre la base de saberes analíticos, que ven la realidad de forma compartimentada y fragmentada". 3

De fato, não nos interessa compartimentar a escrita e nem o tempo. O rigor da cronologia dos calendários além de ser fruto de convenções, de uma ficção, engessaria o fluxo dos eventos trazidos pela memória. Assim, pensamos o tempo desta escrita recorrendo ao tempo das vidas da autora e das avós - mulheres que inspiram -, mas este não é o único tempo aqui evocado. 0 tempo das reminiscências, o tempo dos lugares, o tempo dos sentimentos percorrem cada linha da narrativa.

3 "A ideia de que cada um de nós é um todo físico-químico-biológico-psicológico-sócio-cultural, integrado ao enredo complexo do universo. [...]. Vivemos em um mundo que não pode mais ser entendido com base no conhecimento analítico, que vê a realidade de maneira compartimentada e fragmentada". (CASTRO-GOMEZ, 2009, p. 87)
Assim, se o desenrolar do texto está preso em algum tempo, é no tempo de todas as coisas que nos afectam, de tudo que percebemos trazer de longo tempo, ensinamentos ancestrais que localizamos, quiçá, nas cozinhas das avós, nos olhares trocados no encontro entre aquela que acabou de nascer e aquela que, sentada em sua antiga cadeira de todas as horas, retira forças de um cantinho do corpo para segurar a nova vida nos braços carinhosos e enrugados com um tipo de ruga que cheira a amor, que convida para um abraço, que faz chorar. No encontro com a tataraneta, minha avó Nice Costa, ao olhar-lhe encantada e demoradamente, parecia "costurar e recosturar lembranças em sua casa" (COUTO, 2003 p. 230).

A casa de minha avó materna sempre me encantou. Mais importante ainda, minha avó me encantava e encanta. Desde que me lembro, ela tinha cabelos brancos, bem brancos, lindos e cheios. Cabelos brancos que contrastavam com sobrancelhas espessas e escuras! Sempre presos em um rabo de cavalo. Gostava de abraçá-la, sempre cheirava tão bem! Suas roupas eram simples, discretas, elegantes e perfumadas. Sinto mesmo que "Toda roupa recebe a alma de quem a usa." (COUTO, 2003, p. 163). Lembro-me de vê-la hidratando-se após o banho, quando se arrumava para ir trabalhar ou ir ao supermercado. Qualquer vez que saía de casa estava sempre muito aprumada e altiva. Não usava qualquer acessório, nem mesmo um relógio, mas tinha um porta-joias que herdei. Sou sua primeira neta e ela me deu todos os seus adornos, não deixei de usar um sequer. Há uma blusa de frio com que me presenteou, que, mesmo após tantas lavadas, consigo sentir seu perfume toda vez que a uso. A este respeito aprendi que, mesmo sendo uma mulher pobre, de um território subalternizado e sendo ela mesma ocupante de um oficio menosprezado, ainda que essencial, minha avó encontrava nestes momentos, e também quando no 
antigo rádio com caixa de madeira e com resistências que acendiam e brilhavam enquanto enchia sua cozinha com hinos, um tempo para si mesma. Intrigante esta mão dupla do cuidado, que faz com que no cuidado com os outros cuidemos de nós e vice-versa. Estes raros, porém diários momentos, indicavam que "o tempo, depois, tem ilusão de costureiro" (COUTO, 2003 p. 196), mas que também:

É preciso tempo para isso. E é um dos grandes problemas dessa cultura de si fixar, no decorrer do dia ou da vida, a parte que convém consagrar-lhe. Esse tempo não é vazio: ele é povoado por exercícios, por tarefas práticas, atividades diversas. Ocupar-se de si não é uma sinecura. Existem os cuidados com o corpo, os regimes de saúde, os exercícios físicos sem excesso, a satisfação, tão medida, quanto possivel das necessidades. [...]: trata-se de um longo trabalho de reativação dos princípios gerais e de argumentos racionais que persuadem a não deixarse irritar com os outros nem com os acidentes, nem tampouco com as coisas. (FOUCAULT, 1985, p. 56-57)

Minha avó foi diarista. Trabalhou em muitas casas na Zona Sul do Rio. Em uma trabaIhou por vinte e cinco anos, em outras duas, por trinta anos. Ainda hoje, aos noventa e sete anos traz nos joelhos marcas escuras, sinais dos anos que passou ajoelhada esfregando chãos. Quando não pôde mais exercer este trabalho, passou a lavar e passar roupa. Em alguns dias, seguia nos trens lotados de $\mathrm{Ni}$ lópolis até Botafogo e, em outros dias, para o Leblon e Ipanema. Em uns dias, passava horas lavando roupas e, em outros, passando, isso já com setenta e cinco anos de idade. Já não me lembro quando ou com que idade ela caiu das escadarias da plataforma e quebrou as costelas, mas nem assim interrompeu sua lida. Apenas uma fratura no fêmur anos depois, com mais de oitenta anos, a obrigou a parar.

Lembro que, muitas vezes, ao sair de casa minha vó, avisava que assim que chegasse à estação de trem de Nilópolis iria ao supermercado que ficava bem em frente à plataforma e que deveríamos encontrá-la para ajudar a trazer as bolsas de compras. Quando criança, não entendia o peso de toda esta labuta sobre seu corpo, não entendia a força que uma mulher pobre precisa ter para exercer a função de chefe de família. Eu sempre the pedia para comprar uma fatia de bolo confeitado e minha vó sempre comprava. E lembro de vê-la feliz me observando comer. Hoje me pergunto porque ela não comprava uma fatia para si, e também lembro de perguntar-lhe se queria um pedaço e de toda vez receber um não como resposta. Hoje aquele não me incomoda. Identifico nas considerações de Certeau sobre o "Lugar do corpo, lugar da vida", a casa de minha avó. Assim diz o historiador:

Aqui os corpos se lavam, se embelezam, se perfumam, têm tempo para viver e sonhar. Aqui as pessoas se abraçam e depois se separam. Aqui o corpo doente encontra refúgio e cuidados, provisoriamente dispensado de suas obrigações de trabalho e de representação no cenário social. Aqui o costume permite passar o tempo 'sem fazer nada', mesmo sabendo que 'sempre há alguma coisa a fazer em casa'. Aqui a criança cresce e acumula na memória mil fragmentos de saber e de discurso que, mais tarde, determinarão suas maneiras de agir, de sofrer, de desejar. (CERTEAU, 2013, p. 205)

Entre tantos fragmentos de saber, aprendi sobre a venda de sua força de trabalho, único bem de interesse do capital, e sobre o duplo lucro resultante desta venda, a exploração desmedida, da vantagem abusiva extraída de sua mão de obra desde a juventude até a velhice. Aprendi sobre a duração extenuante de seu labor, sobre as longas horas de trabalho que a obrigavam, a antes de chegar em casa, passar tarde da noite no supermercado. Este sem-fim de tarefas a realizar evidencia a afirmação de Angela Davis de que "Proporcionalmente, as mulheres negras sempre traba- 
Iharam mais fora de casa do que suas irmãs brancas. 0 enorme espaço que o trabalho ocupa hoje na vida das mulheres negras reproduz um padrão estabelecido durante os primeiros anos da escravidão" (DAVIS, 2016, p. 17).

De fato, o trabalho doméstico é carregado das brutalidades da herança e da mentalidade escravocrata. Além disto, "a clivagem entre economia doméstica e economia pública, provocada pelo capitalismo industrial, instituiu a inferioridade das mulheres com mais força do que nunca" (DAVIS, 2016, p. 12).

A herança colonial produziu no Brasil efeitos semelhantes ao que a filósofa afro-americana verificou nos Estados Unidos, em relação ao trabalho doméstico. Minha avó, que parou de trabalhar antes de 26 de março 2013, quando, durante o governo da então presidente Dilma Vana Rousseff, se aprovou o projeto de emenda constitucional conhecido como 'PEC das Domésticas', jamais gozou de direito à férias, 13ㅇ salário etc. A aprovação obrigou que direitos básicos, como jornada de trabalho de 8 horas diárias e 44 horas semanais, pagamento de horas extras e adicional noturno, fundo de garantia por tempo de serviço e seguro-desemprego, fossem estendidos à categoria, jamais a beneficiou.

Como diarista, sua tarefa era higienizar as casas. De joelhos, devia deixar o chão brilhando, de pé, aos setenta e cinco anos, deveria lavar, deixar de molho, engomar, quarar, passar, pendurar de maneira que os cabides não deixassem marcas de dobras nas roupas. A este respeito é possivel pensar com Alain Corbin (1987) que a assepsia exigida para as casas ressoam um aprendizado ou uma atitude difundida pelos higienistas do século XIX, que ensinavam, ou melhor, criavam uma nova sensibilidade olfativa sobre "o hálito da casa". o historiador francês afirma que:

Já em 1762, o abade Jacquin convidava à luta contra os maus odores dos apartamentos e a manter-se limpa a cozinha. Aconselhava que se evitassem o uso excessivo de água e dos vernizes e o desprendimento de fumaças, bem como a presença de cães e gatos nos quartos. Recomendava que se afastassem destes as 'comodidades' e que se mantivessem abertas as cortinas. [...]. Mas após os alarmes, a nova insistência na questão, a coerência dos conselhos ressaltam a rápida evolução que se opera na psicologia coletiva. [...] a desodorização [...], implicava o recuo para dentro de casa, a constituição da esfera do privado. (CORBIN, 1987, p. 207-208)

Ainda que toda esta purificação da casa fosse dirigida ao homem burguês, o modelo de higiene doméstica, a higiene da família, através da imposição dos rigores das normas vai se aplicando sobre o restante da população, e, com o tempo, ganha outros significados, ao invés dos ares de prescrição torna-se expressão de cuidado. As maneiras de limpar ordenadas para os navios: "Arejar, bater, deslocar, desentocar com a vassoura a ameaça dos cantinhos [...], lutar contra a poeira [...], desembaraçar os móveis e os diferentes cômodos de seu ar viciado, de extirpar os fedores, de pôr-se adiante da putrefação" (CORBIN, 1987, p. 218), ao longo do tempo, vão sendo incorporadas aos cuidados com as moradias, e acabam ressignificadas, reinventadas.

Na casa de minha avó, as práticas ordinárias eram reinventadas à perfeição, até porque se as técnicas de higienização foram pensadas para odorizar espaços e narizes burgueses, toda prática foi executada por mulheres oprimidas. As mãos de mulheres pobres, de muIheres negras, portando bucha e sabão, esfregaram a sujeira, limparam o mundo (e o verbo pode ser flexionado no presente). Elas aprenderam a comprar as marcas de sabão, detergentes, desinfetantes, esponjas, escovas e repetiam em suas casas "os gestos codificados da limpeza cotidiana" (CORBIN, 1987, p. 218)

A casa de minha avó, mesmo durante os anos em que estava em construção e as por- 
tas e janelas de madeira eram improvisadas, era o lugar de onde eu não queria sair. Não sei como, mas o banheiro sempre limpíssimo tinha sobre a pia, em um vaso antigo que ela ganhara para compor seu enxoval, uma jiboia sempre verdinha. Recentemente, pergunteithe sobre a planta, e ela me disse que ninguém nunca reparou ou deu valor, então retirou de lá. Mas eu reparei, eu via a planta, mas parece que não demonstrei o prazer que me proporcionava. Entendi depois seu esforço para nos proporcionar um lugar bonito e asseado para morar. Ela parecia saber que "O território onde se desdobram e se repetem dia a dia os gestos elementares das 'artes de fazer' é antes de tudo o espaço doméstico, a casa da gente" (CERTEAU, 2013, p. 204).

Eu desejei durante toda minha infância, adolescência e juventude, jamais sair de perto de minha avó. Eu aprendi tanta coisa, e hoje a percebo em meus gestos, na forma como arquiteto minha moradia, nas maneiras com que me apresento e nas coisas a que atribuo importância. O professor, teólogo e escritor Leonardo Boff, indica que "o que se opõe ao descuido e ao descaso é o cuidado. Cuidar é mais que um ato; é uma atitude. Portanto, abrange mais que um momento de atenção, de zelo e de desvelo. Representa uma atitude de ocupação, preocupação, de responsabilização e de envolvimento afetivo com o outro" (BOFF, 1999, p. 12, grifos do autor). Minha avó exercia o cuidado. E com ela tenho aprendido e confirmado a reflexão de Certeau, de que:

Mesmo um quarto de hotel, anônimo, diz muito sobre seu hóspede de passagem no fim de algumas horas. Um lugar habitado pela mesma pessoa durante um certo tempo esboça um retrato semelhante, a partir dos objetos (presentes ou ausentes) e dos costumes que supõem. 0 jogo das exclusões e das preferências, a disposição do mobiliário, a escolha dos materiais, a gama de formas e de cores, as fontes de luz, o reflexo de um espelho, um livro aberto, um jor- nal pelo chão, uma raquete, cinzeiros, a ordem e a desordem, o visivel e o invisivel, a harmonia e as discordâncias, a austeridade ou a elegância, o exotismo e mais ainda a maneira de organizar o espaço disponivel, por exíguo que seja, e de distribuir nele as diferentes funções diárias (refeições, toalete, recepção, conversa, estudo, lazer, repouso), tudo já compõe um 'relato de vida', mesmo antes que o dono pronuncie a mínima palavra. 0 olhar atento reconhece imediatamente a confusão dos fragmentos do 'romance familiar', o traço de uma encenação destinada a dar uma certa imagem de si, mas também a confissão involuntária de uma maneira mais intima de viver e de sonhar. Neste lugar próprio flutua como que um perfume secreto, que fala do tempo perdido, do tempo que jamais voltará, que fala também de um outro tempo que virá, um dia quem sabe. (CERTEAU, 2013, p. 204)

Sobre o tempo que virá, é possivel dizer que minha avó sempre esteve muito atenta. Antes do primeiro tijolo assentado, ela já se mostrava preocupada com a solidez da construção, sobre a capacidade da casa que estava edificando poder sustentar uma outra sobre sua estrutura. Por vezes me dizia que quando eu crescesse poderia morar no segundo piso, depois foi esticando as funcionalidades e os possíveis moradores. Passou a dizer então, que era importante ter uma alternativa, caso, no futuro, um filho ou filha, um neto ou neta precisasse. E foi o que ocorreu. Minha avó com seu cansativo trabalho como diarista, possuía um plano e uma força extraordinária para garantir uma moradia aos seus descendentes. Ela nunca foi impedida pelos argumentos daqueles que zombavam de seu "moinho de vento", nem ela nem tantas outras mulheres negras, pobres, chefes de família. Chefes natas, líderes, que se ocupam de fabricar táticas de sobrevivência para o presente e para o futuro. Minha vó sabia que a casa é:

O território onde se desdobram e se repetem dia a dia os gestos elementares das 'artes de 
fazer' é antes de tudo o espaço doméstico, a casa da gente. De tudo se faz para não 'retirarse' dela porque é o lugar 'em que a gente se sente em paz'. 'Entra-se em casa', no lugar próprio que por definição não poderia ser o lugar de outrem. Aqui todo visitante é um intruso, a menos que tenha sido explícita e livremente convidado a entrar. [...] Este território privado é preciso protegê-lo dos olhares indiscretos, porque cada um sabe que o mínimo apartamento ou moradia revela a personalidade de seu ocupante. (CERTEAU, 2013, p. 203-204)

A casa da minha avó é simples, mas é rica. É rica porque possui um valor estabelecido em nossas memórias, pela função que ela cumpre. É o lugar da infância de todos os netos, o lugar do natal, da rabanada, do pastel de forno da tia, do pudim de laranja da avó. É o lugar de proteção para onde se corria quando queríamos fugir dos pais, das consequências de traquinagens e peraltices. É lá que ficava a mesa do café com leite e do pão com manteiga garantido durante a semana e da fatia de bolo confeitado nos finais. É o lugar em que os primos se reuniam para brincar e gritar, onde sobrinhos encontravam tios, se abraçavam e escapavam dos pais para sair com eles e com o avô para lugares e eventos que só eles conheciam os caminhos, como o samba de fundo de quintal em Anchieta. É neste território que as crianças pediam brinquedos aos tios e avós, onde, apesar do pouco estudo, os mais velhos sonhavam grandes conquistas para os pequenos. Um desavisado poderia ficar preso ao fato de que "Indiscreto, o habitat confessa sem disfarce o nivel de renda e as ambições sociais de seus ocupantes. Tudo nele fala sempre e muito: sua situação na cidade, a arquitetura do imóvel, a disposição das peças, o equipamento de conforto, o estado de manutenção" (CERTEAU, 2013, p. 204), mas neste habitat havia mais coisas.

Minha avó aproveitou cada canto do pequeno terreno que conseguiu adquirir. To- dos os compartimentos cumpriam bem as funções que lhes foram destinadas. As funções iam desde prover condições para coisas práticas como a lavagem das louças e roupas, bem como garantir a convivência entre todos, o descanso, a distração. Tudo foi comprado para durar, não havia muito como alterar o lugar das coisas, elas deviam permanecer onde estavam para que muitos pudessem usufruir. Ainda assim, vez por outra, minha avó encontrava pequenas mudanças que fazíamos para agradá-la. Afinal:

A diversidade dos lugares e das aparências nem se compara à multiplicidade das funções e das práticas de que o espaço privado é ao mesmo tempo o cenário próprio para mobiliar e o teatro da operação. Aqui se repetem em número indefinido em suas minuciosas variações as sequências de gestos indispensáveis aos ritmos do agir cotidiano. Aqui o corpo dispõe de um abrigo fechado onde pode estirar-se, dormir, fugir do barulho, dos olhares, da presença de outras pessoas, garantir suas funções e seu entretenimento mais intimo. (CERTEAU, 2013, p. 205)

Quando criança, eu dormia algumas vezes no quarto de meus avós maternos, em alguns dias eu ouvia minha vó se levantar. Ela saía da cama com muito cuidado, os chinelos já estavam esperando-a na beirada, deixava o quarto sem acender a luz. Eu olhava tudo isso quietinha sob a coberta. As janelas do quarto sempre ficaram abertas e eu podia ver que ainda estava escuro na rua. Mesmo em Nilópolis, eu ouvia um galo cantando em algum lugar. Com o passar do tempo, aprendi que o horário fiel que minha vó se punha em pé era três horas da manhã. Do colchão no quarto, eu sentia minha vó em suas primeiras ações na cozinha. Ela acordava tão cedo para deixar o almoço pronto. A casa ficava cheia do cheiro de sua comida perfumada. A pia, os azulejos da parede, a cerâmica do chão, o uniforme para a escola, as mesinhas para o café da manhã, ficavam orga- 
nizadas, tudo carinhosamente arrumado. Com minha avó, aprendi sobre o amor em forma de cuidado. Coisa tão importante, a ponto de:

Mitos antigos e pensadores contemporâneos dos mais profundos nos ensinam que a essência humana não se encontra tanto na inteligência, na liberdade ou na criatividade, mas basicamente no cuidado. 0 cuidado é, na verdade, o suporte real da criatividade, da liberdade e da inteligência. No cuidado se encontra o ethos fundamental humano. Quer dizer, no cuidado identificamos os princípios, os valores e as atitudes que fazem da vida um bem-viver e das ações um reto agir. (BOFF, 1999, p. 2)

Minha avó criou três netos. Mesmo que seus ombros suportassem o peso do mundo, levou-os para tratamento psicológico, jamais faltando consulta. Enfrentou as longas filas do INAMPS ${ }^{4}$ feito a fim de garantir cirurgia de otoplastia estética para um e de hiperidrose para outro; procurou meios de curar-lhes dos problemas do espírito e do corpo, ela sabia que tudo estava interligado. Quando menina, sonhou em ser enfermeira, mas o pai the permitiu frequentar a escola apenas o suficiente para aprender a assinar o seu nome. Mas fezse enfermeira em casa. Mantinha um pequeno armário no corredor dos fundos cheio de medicamentos com os quais sempre nos curava; lembro-me de vê-la lendo bulas repetidas vezes para aprender como desenvolver melhor suas práticas de cuidado de si e dos outros. Vale pensar que "Em torno dos cuidados consigo toda uma atividade de palavra e de escrita

4 INAMPS - Instituto Nacional de Assistência Médica da Previdência Social. O INAMPS constituía-se como a política pública de saúde que vigorava antes da criação do SUS e foi extinto pela lei federal 8.689, em 1993. O antigo Instituto era responsável pela assistência médica aos trabalhadores que contribuíam com a previdência social. Os setores da população que não faziam esta contribuição não podiam acessar estes serviços. Com a criação do SUS, o atendimento passou a ser universal, ou seja, qualquer pessoa pode acessar o serviço público de saúde em qualquer parte do país. Disponivel em: <http:/ /www.epsjv.fiocruz.br/ instituto-nacional-de-assistencia-medica-da-previdencia-social-inamps>. Acesso em: 20 jan. 2019. se desenvolveu, na qual se ligam o trabalho de si para consigo e a comunicação com outrem. Tem-se aí um dos pontos mais importantes dessa atividade consagrada a si mesmo: ela não constitui um exercício de solidão, mas sim uma verdadeira prática social" (FOUCAULT, 1985, p. 57).

Nas raras vezes em que me levantei da cama seguindo minha vó para a cozinha, a encontrei consertando buracos de panelas e leiteiras com algodão. Mesmo calada em um canto da cozinha, eu ficava esperando que o leite vazasse pelos buracos assim que o algodão pegasse fogo, mas isto nunca aconteceu. Minha avó era formada na ciência de remendá -las, assim como era instruída na arte cuidadosa do preparo dos alimentos. Não admitia que dormíssemos sem comer. Todas as noites, mesmo tendo jantado, nos fazia tomar um gostoso mingau preparado com frutas e aveia. Ela dormia tão pouco, comia tão pouco, é um mistério ter se tornado uma fortaleza.

Enfim, não é simples escrever um artigo "científico" que tem, entre outros interesses, provocar um desconforto no próprio fazer da ciência e interrogar sobre a presunção de que a verdade e a definição da relevância dos temas seja sua propriedade, pois, para ser ouvido, lido e considerado, por vezes faz-se necessário recorrer às práticas que se interroga. Ainda assim, permaneço no intento e no desafio de demonstrar, ou melhor, de registrar a existência e a força de uma pedagogia, de um conjunto de saberes e propósitos, de metodologias, elaboradas no interior de algumas casas.

Abro um breve parêntese pala contar que certa vez o adolescente $\mathrm{CM},{ }^{5}$ aprisionado no

5 Narrativa colhida durante entrevista realizada com o adolescente CM no ano de 2004, quando o mesmo se encontrava aprisionado no Centro Socioeducativo Pomeri em Cuiabá, MT. Esta e outras narrativas compõem os cadernos de campo da autora e algumas figuram na obra "POMERI: Espaço de Reclusão - Máquina de Guerra", publicada em 2011, pela Câmara Brasileira de Jovens Escritores. 
Centro Socioeducativo Pomeri, durante atendimento com uma assistente social, ensinou que "nem toda casa na rua é igual, tem casa que tem comida todo dia, tem casa que tem comida de vez em quando, tem casa que não tem comida nunca, a minha não tinha mais comida". Nem todas as famílias gozam de casa, nem todas as pessoas possuem famílias, nem todas as famílias estão empenhadas no cuidado de si e dos outros. As desigualdades e diferenças sociais impedem a existência de famílias e a constituição dos laços sobre os quais tratamos neste artigo. Ainda assim, algumas famílias, e não falamos de famílias assentadas no modelo judaico-cristão capitalista, mas de famílias pobres, de famílias negras, via de regra comandadas por mulheres, sobrevivem e põe em andamento redes de afeto, proteção e ensinamentos.

Neste artigo, quisemos publicizar nosso reconhecimento à pedagogia de nossas avós e aos ensinamentos guardados em suas casas. Minha avó materna, hoje com 97 anos de idade, sempre me protegeu, me encheu de amor e de ensinamentos. Sua perseverança tem me inspirado ao longo da vida e me feito seguir em frente. Sua história, como a de tantas outras mulheres pobres, negras, que sobrevivem a longas jornadas de trabalho, merece uma escrita que ponha em perspectiva o quanto sustentam a sociedade, o quanto são sábias, o quanto asseguram a vida. Não são histórias esparsas e raras, elas se desenrolam em muitas casas das periferias, entre os mais pobres. Apesar das mulheres da idade e da classe social de minha vó não terem cursado mais que o ensino fundamental, elas precisam ser ouvidas, sentidas, aprendidas. Não são estas mulheres que precisam de minha escrita, sou eu, meus filhos e minha neta que precisamos de sua sabedoria. Elas possuem a ciência de circular pelos bairros onde moram, de conhecer as bancas dos feirantes, açougueiros e padei- ros, é com eles que conversam sobre a carestia, sobre o peso dos produtos, pois eles acabarão nos pratos de seus filhos e netos.

Suspeito que todo este edificio de cuidados que constroem em volta de seus filhos e de sua descendência tenham origem muito antiga. Não sei e não preciso datar. Mas agora que encerro estas primeiras notas, fico pensando nas abayomis, bonecas negras feitas por mulheres africanas negras escravizadas pela empresa colonizadora europeia, com retalhos de seus andrajos, para entreter e proteger espiritualmente as crianças postas nos mesmos porões dos infames navios negreiros.

À nossas avós, à nossas ancestrais, às mulheres negras de hoje e de todos os tempos e lugares, talvez a poesia seja razoavelmente eficiente nas palavras para dizer que suas vidas nos ensinam.

\section{VOZES-MULHERES}

Conceição Evaristo (2008, p. 11)

A voz de minha bisavó
ecoou criança
nos porões do navio.
Ecoou lamentos
de uma infância perdida.
A voz de minha avó
ecoou obediência
aos brancos-donos de tudo.
A voz de minha mãe
ecoou baixinho revolta
no fundo das cozinhas alheias
debaixo das trouxas
roupagens sujas dos brancos
pelo caminho empoeirado
rumo à favela.
A minha voz ainda
ecoa versos perplexos
com rimas de sangue
e
fome.

A voz de minha bisavó

nos porões do navio.

Ecoou lamentos

de uma infância perdida.

ecoou obediência

aos brancos-donos de tudo.

A voz de minha mãe

ecoou baixinho revolta

no fundo das cozinhas alheias

roupagens sujas dos brancos

pelo caminho empoeirado

rumo à favela. 
A voz de minha filha

recolhe todas as nossas vozes

recolhe em si

as vozes mudas caladas

engasgadas nas gargantas.

A voz de minha filha

recolhe em si

a fala e $o$ ato.

O ontem - o hoje - o agora.

$\mathrm{Na}$ voz de minha filha

se fará ouvir a ressonância

o eco da vida-liberdade.

Sobre Marieta e Nice, com imenso amor.

\section{Referências}

BOFF, Leonardo. Saber cuidar. Ética do humano compaixão pela terra. Petrópolis, RJ: Vozes, 1999.

CASTRO-GOMEZ, Santiago; GROSFOGUEL, Ramon. (Comp.). El giro decolonial: reflexiones para una diversidad epistémica más allá del capitalismo global. Bogotá: Siglo del Hombre Editores; Universidad Central; Instituto de Estudios Sociales Contemporáneos; Pontificia Universidad Javeriana; Instituto Pensar, 2009.

CERTEAU, Michel. A invenção do cotidiano: 2. morar, cozinhar. Petrópolis, RJ: Vozes, 2013.
CORBIN, Alain. Saberes e odores: o olfato e o imaginário social nos séculos XVIII e XIX. São Paulo: Companhia das Letras, 1987.

COUTO, Mia. Um rio chamado tempo, uma casa chamada terra. São Paulo: Companhia das Letras, 2003.

DAVIS, Angela Y. Mulheres, raça e classe. São Paulo: Boitempo, 2016.

EVARISTO, Conceição. Poemas da recordação e outros movimentos. Belo Horizonte: Nandyala, 2008.

FOUCAULT, Michel. História da sexualidade. 3. O cuidado de si. Rio de Janeiro: Edicões Graal, 1985.

GROSFOGUEL, RAMÓN. Los derechos humanos y el antisemitismo después de Gaza. Bogotá: Universitas Humanística 2009. (texto em pdf).

MONTEIRO, Silas Borges. Uivo otobiográfico. Revista Linha Mestra, n. 31, p. 17-20, jan./abr. 2011.

NIETZSCHE, Friedrich. Além do bem e do mal. Tradução de Paulo César Lima de Souza. São Paulo: Cia. das Letras, 2009.

SCUDDER, Priscila de Oliveira Xavier. Pomeri: Espaço de Reclusão - Máquina de Guerra. Rio de Janeiro: Câmara Brasileira de Jovens Escritores, 2011.

Recebido em: 25/01/2019

Aprovado em: 09/04/2019

Priscila de Oliveira Xavier Scudder é Doutora em Educação. Professora do Programa de Pós-Graduação em Educação da Universidade Federal de Mato Grosso, Rondonópolis, MT - Brasil. Coordenadora do Grupo de Pesquisa - Observatório: Poder, Cultura e Contemporaneidade. e-mail: mj007nz@gmail.com

Universidade Federal de Mato Grosso. Avenida dos Estudantes, 5055 - Cidade Universitária, Rondonópolis, MT. CEP: 78735-901. Telefones: (66) 3410-4000 (66) 99943.3141 